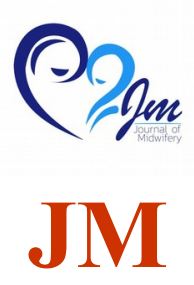

Volume 8 No. 1 (April 2020)

(C) The Author(s) 2020

\title{
EFEK AROMA TERAPI LAVENDER MENGURANGI NYERI NIFAS
}

\author{
EFECT LAVENDER AROMA TERAPY REDUCE PUERPERIUM PAIN \\ DENI MARYANI, DARA HIMALAYA \\ PRODI D3 KEBIDANAN FAKULTAS MIPA UNIVERSITAS BENGKULU \\ Email: dmaryani@unib.ac.id
}

\begin{abstract}
ABSTRAK
Pendahuluan: Nyeri pada masa nifas dapat berpengaruh pada wanita dalam proses mobilisasi dan menimbulkan efek negatif pada waktu hamil, bersalin, dan nifas berikutnya. Nyeri pada masa nifas apabila tidak ditangani dengan baik dapat menimbulkan komplikasi akibat pasien takut untuk mobilisasi seperti infeksi masa nifas dan perdarahan.Pemberian terapi nonfarmakologi menjadi alternatif karena tidak memberikan efeksamping, salah satu terapi nonfarmaklogi itu adalah dengan pemberian aromaterapi minyak esensial lavender, lavender memiliki sifat antikonfulsan, antidepresi, dan menenangkan. Aroma terapi lavender pada saat dihisap akan merangsang hipotalamus mengeluarkan hormon endorphin yang dikenal dengan hormon kebahagiaan dan menimbulkan efek mengurangi rasa nyeri. Tujuan penelitian ini untukmengetahui efek aromaterapi lavender mengurangi nyeri nifas.Metode: Penelitian ini merupakan tinjauan literatur (literature review) dengan metode naratif yang mencoba menggali hasil penelitian terkait dengan pengaruh aroma terapi lavender.Sumber pencarian data melalui database terkomputerisasi dari google cendekia (google sholar) dari tahun 2010 sampai tahun 2019 Kriteria pemilihan hasil penelitian dari jurnal nasional dan internasional.Hasil: penelitian yang didapat menggunakan metode quasi eksperimen, aromaterapi lavender efektif mengurangi nyeri pada masa nifas. Kesimpulan: aromaterapi lavender terjadi pengurangan nyeri nifas ditandai dengan ibu merasa rileks, nyaman.
\end{abstract}

Kata kunci: lavender, nyeri, nifas

\begin{abstract}
Introduction: Pain during the puerperium can affect women in the process of mobilization and cause negative effects during pregnancy, childbirth, and subsequent postpartum. Pain during the puerperium if not handled properly can cause complications such as puerperal infection and bleeding. Giving nonpharmacology is an alternative because it does not provide side effects, one of the nonpharmacological therapies is by giving aromatherapy of lavender essential oil, lavender has anticonfulsan, antidepressant, and calming properties. The aroma of lavender therapy when smoked will stimulate the hypothalamus to release endorphin hormone, known as the hormone of happiness and cause the effect of reducing pain. The purpose of this study was
\end{abstract}


to determine the effects of lavender aromatherapy in reducing puerperal pain. Method: This research is a literature review (narrative review) with a narrative method that tries to explore the results of research related to the influence of the aroma of lavender therapy. Sources of data search through a computerized database from Google Scholar (Google Sholar) from 2010 to 2019 Criteria for selecting research results from national and international journals. Results: the study obtained using the quasi-lavender aromatherapy experimental method effectively reduces pain in the puerperium. Conclusion: lavender aromatherapy is a reduction in puerperal pain characterized by mothers feeling relaxed, comfortable.

\section{Keywords: lavender, pain, puerperium}

\section{PENDAHULUAN}

Masa nifas (puerperium) adalah masa pulih kembali, mulai dari persalinan selesai sampai alat-alat kandungan kembali seperti sebelum hamil. Lama masa nifas 6-8 minggu. (Mochtar, 2010) Hal penting dalam masa nifas dengan menjaga kesehatan ibu dan bayinya baik fisik maupun psikologis dimana dalam asuhan pada masa ini peranan keluarga sangat penting, dengan memberikan nutrisi, dukungan psikologis maka kesehatan ibu dan bayi terjaga. Asuhan masa nifas sangat penting dan diperlukan karena dalam periode ini disebut masa kritis baik pada ibu maupun bayinya. Diperkirakan insiden kematian ibu di Indonesia sebesar $60 \%$ terjadi pada masa post partum dan sebesar $50 \%$ kematian masa nifas terjadi dalam 24 jam pertama (Kemenkes, 2015) ibu nifas sering merasakan keluhan selama pasca melahirkan, keluhan yang sering dirasakan ibu nifas diantaranya nyeri perut bagian bawah disebabkan karena involusi atau terjadi kontraksi, nyeri akibat luka laserasi. (Maryunani, 2016).

Setiap orang berbeda penerimaan ambang nyerinya, sebagian orang akan merasa terganggu dengan keadaan nyeri nifas terutama nyeri pada daerah perineum. Pada ibu post partum keadaan nyeri perineum adalah hal yang fisiologis, namun apabila seseorang tidak dapat beradaptasi dengan nyeri tersebut dapat mengganggu aktifitas ibu sehari-hari dan dapat berpengaruh pada mobilitas ibu yang dapat menyebabkan komplikasi lain seperti infeksi nifas, dan perdarahan.Nyeri yang disebabkan oleh laserasi dan kontraksi dapat menyebabkan ketidaknyamanan pada ibu.East (2010) melaporkan dari hasil penelitiannya di rumah sakit Royal Victoria di Australia terjadi 90\% ibu nifas mengalami nyeri perineum, 33\% nyeri dirasakan ketika berjalan, 39\% ketika duduk, dan 45\% ketika berbaring. Bentuk nyeri yang dialami ibu nifas adalah nyeri akut, nyeri ini dapat menjadi menakutkan dan akan berdampak negatif terhadap pengalaman menjadi seorang ibu, oleh sebab itu nyeri dalam masa nifas harus mendapat penanganan yang serius dan penting untuk di atasi.

Nyeri dapat diatasi dengan cara farmakologi dan non farmakologi, terapi farmakologi dengan menggunakan obatobatan yang dapat mengurangi rasa nyeri analgesik, dari hasil penelitian untuk mengatasi rasa nyeri sebagian besar wanita akan menggunakan obat pengurang rasa nyeri analgetik dan ice pack sebesar 69\%, sedangkan dengan meminum obat anakgesik sebesar 75\%. (East, 2010).Pada tipe terapinon farmakologi untuk dapat mengurangi rasa nyeri dapat digunakan dengan carateknik relaksasi, massage, kompres, terapi musik, murottal, dan aroma terapi. (Smeltzer, 2002).

Teknik non farmakologi banyak digunakan untuk mengatasi nyeri masa nifas, selain itu juga pengobatan atau terapi dengan non farmakologi tidak memiliki efek samping.Alternatif yang digunakan untuk pengobatan non farmakologi adalah dengan menggunakan aroma terapi. Aroma terapi berasal dari kata aroma yang memiliki arti harum atau wangi, therapy diartikan cara pengobatan, sehingga aroma therapy diartikan suatau cara penyembuhan penyakit dengan menggunakan minyak essensial. (Jaelani, 
2009) Aromaterapi yang sering digunakan antara laincendana, kemangi, cengkih, lavender, kenanga, kayu manis, melati, cengkih, mawar jasmine. Lavender banyak dikembangkan didunia karena memiliki banyak khasiat dikenal sebagai minyak penenang, efek sedatif, anti konvulsan, antidepresi, anxiolytic, dan bersifat menenangkan.ini terjadi karena adanya senyawa-senyawa coumarin dalam minyak tersebut. (Koensoemardiyah, 2009).

Zat aktif yang terkandung didalam aroma terapi lavender akan merangsang hipotalamus untuk memproduksi dan mengeluarkan endorpin proses ini terjadi pada saat aroma terapi dihisap. Endorpin sebagai zat yang menimbulkan rasa tenang, relaks, dan bahagia, endorpin dikenal dengan hormon kebahagiaan dan memiliki efek sebagai analgetik. (McCullough, 2018) pemberian aroma terapi dengan inhalasi dilakukan dengan berbagai cara dengan dihisap ditisu, dihirup melalui telapak tangan, dan penguapan. (Dwijayanti, 2014) tujuan dari penelitian ini untuk mengetahui efek aroma terapi lavender terhadap pengurangan nyeri nifas.

\section{METODE PENELITIAN}

Penelitian ini merupakan tinjauan literatur (literature review) dengan metode naratif yang mencoba menggali hasil penelitian terkait dengan pengaruh aroma terapi lavender terhadap pengurangan nyeri nifas. Sumber pencarian data melalui database terkomputerisasi dari google cendekia (google sholar) dari tahun 2010 sampai dengan tahun 2019 tentang penggunaan penggunaan aroma terapi lavender berjumlah 12 jurnal penelitian. Hasil penelitian dipilih berdasarkan tema yang sesuai dengan judul artikel dan sudah dipublikasikan baik prosiding maupun jurnal. Kriteria pemilihan hasil penelitian jurnal nasional dan internasional.

\section{HASIL PENELITIAN}

Masa nifas adalah masa setelah melahirkan hingga alat kandungan kembali seperti keadaan sebelum hamil dan dalam waktu kurang lebih 6 minggu.(Mochtar, 2010) Menjaga kesehatan ibu baik fisik maupun psikologis sangat diperlukan pada masa periode ini karena pengalaman masa hamil, melahirkan, dan nifas akan memberikan dampak yang positif bagi ibu, sebaliknya bila masa ini memberikan pengalaman yang tidak baik akan menimbulkan dampak negatif yang akan berpengaruh pada kondisi ibu baik fisik maupun psikis, secara fisik bila ibu nifas takutdengan rasa nyeri bisa berakibat ibu takut untuk bergerak sehingga dapat menyebabkan komplikasi seperti infeksi nifas dan perdarahan masa nifas.

Artikel pertama merupakan penelitian yang dilakukan oleh Widayani (2016) dengan menggunakan metode quasi eksperimen dengan rancangan one group pre dan post test, tempat penelitian di kota Bandung sampel 28 responden hasil penelitian menyatakan ada penurunan nyeri sebelum dan setelah pemberian aromaterapi lavender secara inhalasi, pemberian aromaterapi lavender berpengaruh terhadap penurunan intensitas nyeri luka perineum.

Artikel ke dua penelitian yang dilakukan oleh Anwar dengan judul pengaruh aromaterapi lavender terhadap penurunan intensitas nyeri pasien pasca operasi section caesaria di RSUD Dr. H. Abdul Moeloek Lampung, metode penelitian quasi eksperiment rancangan nonequivalent control group, instrument yang digunakan untuk mengukur tingkat nyeri dengan alat ukur Numerical Rating Scale dengan skala 0-10 pengkajian nyeri dilakukan sebelum dan setelah diberikan aroma terapi lavender pada kelompok perlakuan. Hasil penelitian pada kelompok intervensi menggambarkan ratarata nilai skala sesudah pemberian aromaterapi lavender mengalami penurunan rerata 6.92 menjadi 3.83.hasil penelitian dengan uji Mann-Whitney diperoleh hasil pvalue $(0,000)<\alpha(0,05)$ dapat disimpulkan 
bahwa pemberian aroma therapi lavender berpengaruh terhadap penurunan intensitas nyeri post operasi sectio caesarea. (Anwar, 2018)

Penelitian ke tiga dilakukan dilakukan di Unit Kebidanan dan Ginekologi di Iran, dengan judul penelitian Effect of lavender scent inhalation on prevention of stress, anxiety and depression in the postpartum period, Sampel sebanyak 140 responden (kelompok intervensi dan kelompok control). Analisa data menggunakan Mann whitney, analisis varian menggunakan ANOVA dan tes post hok. Hasil penelitian menunjukkan bahwa rata-rata stres, kecemasan, dan depresi pada titik waktu 2 minggu $(\mathrm{P}=0,012, \mathrm{P}$ $<0,0001$, dan $\mathrm{P}=0,003)$ dan stres, kecemasan, dan skor depresi pada titik waktu 1 bulan $(\mathrm{P}<0,0001)$ dan 3 bulan setelah melahirkan $(\mathrm{P}<0,0001)$ secara signifikan lebih rendah pada kelompok intervensi dibandingkan dengan kelompok kontrol (Kianpour, 2016)

Penelitian keempat Dwijayanti dengan judul efek aromaterapi lavender inhalasi terhadap intensitas nyeri pasca sectio caesaria di RSUD Dr. Adhyatma MPH, rancangan penelitian yang digunakan adalah pre eksperimental design dengan rancangan one group pretest-post testdesign. Sampel yang digunakan adalah pasien pasca sectio caesaria berjumlah 32 responden.Instrument yang digunakan dalam penelitian ini adalah skala numerik (Numerical Rating Scale, NRS) sebelum dan sesudah diberikan aromaterapi lavender. Hasil yang didapat pembuktian hipotesis adanya perbedaan intensitas nyeri pasca sectio caesaria sebelum dan sesudah pemberian aroma terapi lavender secara inhalasi menggunakan uji paired t-test dikarenakan data yang berdistribusi normal. Hasil penelitian didapatkan p value $0,001(<$ $0,05)$ dan hasil $t$ sebesar 9,000 $(>t=2,042)$ hitung tabel yang berarti ada perbedaan yang signifikan antara sebelum dan sesudah pemberian aromaterapi lavender secara inhalasi. (Dwijayanti, 2014).

Penelitian kelima dilakukan oleh Haryanti dengan judul pengaruh pemberian aroma terapi lavender terhadap nyeri pada ibu post sectio caesarea hari pertama di ruang bersalin rumah sakit pertamina bintang amin bandar lampung, Penelitian ini menggunakan pra eksperimen dengan pendekatan one group pretest dan post test. Responden dalam penelitian ini adalah ibu bersalin dengan post sectio caesarea di hari pertama di ruang bersalin RS Pertamina Bintang Amin sebanyak 37 kasus. Analisis univariate dalam penelitian ini menggunakan persentase sedangkan analisis bivariate menggunakan uji $\mathrm{T}$ dependen. Hasil penelitian ini menunjukkan bahwa nyeri pada ibu bersalin post SC hari pertama sebelum pemberian aroma terapi lavender dengan nilai rata-rata (mean) sebesar 5,8378 , sedangkan nyeri pada ibu bersalin post SC hari pertama setelah pemberian aroma terapi lavender dengan nilai rata-rata (mean) sebesar 3,4054. Terdapat pengaruh pemberian aroma terapi lavender terhadap nyeri pada ibu bersalin post SC hari pertama $(\mathrm{p}$ value $=0,000)$. (Haryanti, 2019).

Penelitian keenam oleh Aprina dengan judul latihan slow deep breathing dan aroma terapi lavender terhadap intensitas nyeri pada klien post seksio sesaria Desain penelitian ini menggunakan Quasy Eksperiment dengan rancangan Non-Equivalent Control Group. Jenis penelitian yang digunakan dalam penelitian ini adalah kuantitatif. Populasi dalam penelitian ini adalah pasien post operasi seksio sesaria di RSUD H. Abdul Moeloek Provinsi Lampung.Sampel penelitian ini adalah 60 responden, yang dibagi menjadi 30 kelompok slow deep breathing dan 30 kelompok aromaterapi lavender. Pengumpulan data dilakukan dengan membagi responden menjadi 2 kelompok yaitu kelompok yang akan dilakukan slow deep breathing dan kelompok aromaterapi lavender. Kemudian peneliti bersama responden mengisii lembar NSR sebelum dilakukan tindakan, lalu peneliti melakukan intervensi dan mengkaji ulang skala nyeri setelah dilakukan tindakan Hasil penelitian ada perbedaan latihan slow deep breathing dengan aroma terapi lavender terhadap intensitas nyeri pada pasien pasien 
post sectio sesaria $(P$ value $=0.000)$.

Penelitian ketujuh dilakukan oleh Shikhan dengan judul Episiotomy pain relief: use of lavender oil essence in primiparous Iranian women penelitian dilakukan di rumah sakit Kamali Iran uji klinis melibatkan 60 wanita primipara dengan kategori kelompok kasus dan kelompok control, instrument penilaian nyeri dengan menggunakan visual analogue scale (VAS) dan redness, edema, ecchymosis discharge scale (REEDA).hasil penelitian penggunaan esensi minyak lavender efektif dalam mengurangi ketidaknyamanan perinealsetelah episiotomi. (Sheikhan, 2012)

\section{PEMBAHASAN}

Dari tujuh jurnal yang dipilih menggunakan metode penelitian yang sama yaitu quasi eksperimen aromaterapi esensial lavender dengan inhalasi, penulis menyimpulkan bahwa aromaterapi lavender efektif mengurangi nyeri pada masa nifas baik itu karena nyeri karena laserasi perineum, luka post sectiocesaria. Pemberian aromaterapi lavender tidak memberikan efeksamping.Terapi esensial minyak lavender berpengaruh secara positif terhadap kecemasan dan dapat mengontrol rasa sakit. Aroma terapi lavender dapat menjadi salah satu alternatif penanganan nyeri akibat luka perineum. (Salamati, 2014).

Hasil penelitian menjelaskan bahwa molekul dan partikel lavender saat dihirup akan masuk melalui hidung, kemudian diterima oleh reseptor saraf sebagai signal yang baik dan kemudian diinterpretasikan sebagai bau yang menyenangkan, dan akhirnya sensori bau tersebut masuk serta memengaruhi sistem limbic sebagai pusat emosi seseorang, sehingga syaraf dan pembuluh darah perasaan akan semakin relaks dan akhirnya rasa nyeri berkurang. (Kristianti, 2010).

Membantu ibu dalam mengatasi rasa nyeri nifas diperlukan untuk memberikan rasa rileks, nyaman pada ibu sehingga ibu akan merasa bahagia dalam menjalani masa nifasnya. pemberian aromaterapi lavender berpengaruh terhadap penurunan intensitas nyeri luka perineum. Zat aktif yang terkandung didalam aroma terapi lavender akan merangsang hipotalamus untuk memproduksi dan mengeluarkan endorpin proses ini terjadi pada saat aroma terapi dihisap. Endorpin sebagai zat yang menimbulkan rasa tenang, relaks, dan bahagia, eandorpin dikenal dengan hormon kebahagiaan dan memiliki efek sebagai analgetik. (McCullough, 2018) pemberian aroma terapi dengan inhalasi dilakukan dengan berbagai cara dengan dihisap ditisu, dihirup melalui telapak tangan, dan penguapan. (Dwijayanti, 2014) Pada penelitian ke tiga aromaterapi lavender juga efektif untuk mengurangi kecemasan dan stress pada ibu postpartum di Iran, dan juga untuk mencegah terjadinya depresi postpartum/ postpartum bluesyang dapat mengganggu kepentingan ibu, bayi dan anggota keluarganya. (Kianpour, 2016)

\section{KESIMPULAN}

Berdasarkan analisis yang penulis lakukan terhadap tujuh jurnal yang relevan dan penelitian yang penulis lakukan dapat disimpulkan setelah diberikan aromaterapi lavender terjadi pengurangan nyeri nifas ditandai dengan ibu merasa rileks, nyaman. Terdapat berbagai metode untuk mengurangi rasa nyeri nifas, aromaterapi lavender selain dapat mengurangi rasa nyeri nifas juga dapat mengurangi kecemasan dan mencegah depresi post partum.

Aromaterapi lavender dapat menjadi alternatif pengobatan nonfarmakologi dalam pengurangan rasanyeri pada masanifas yang diakibatkan oleh laserasi perineum, luka post operasi section caesaria aman untuk diberikan dan tidak ada efeksamping.

\section{SARAN}

Saran yang dapat diberikan adalah tenaga kesehatan dapat menggunakan aromaterapi lavender sebagai pengobatan nonfarmakologi 
dan metode alternative dalam mengurangi rasa nyeri pada masa nifas

\section{DAFTAR PUSTAKA}

Anwar M, Astuti T, Bangsawan M. Pengaruh aromaterapi lavender terhadap penurunan intensitas nyeri pasien paska operasi sectio caesarea. Jurnal Keperawatan.2018;XIV(1).84-90.

Aprina, Hartika R, Sunarsih. Latihan Slow Deep Breathing dan Aromaterapi Lavender terhadap Intensitas Nyeri pada Klien Post Seksio Sesaria. Jurnal Kesehatan. 2018;9(2):272-9.

Dwijayanti, W. Efek aromaterapi lavender inhalasi terhadap intensitas nyeri paska sectio caesarea. Med Hosp. 2014;2(2):120-5.

East $\mathrm{CH}$, dkk. Perineal pain following childbirth: prevalence, effects on postnatal recovery and analgesia usage.ELSEVIER.2012;28:93-7.

Haryanti RP, Patria A. Pengaruh pemberian aroma terapi lavender terhadap nyeri pada ibu post sectio caesarea hari pertama di ruang bersalin rumah sakit pertamina bintang amin bandar lampung. MANUJU: MALAHAYATI NURSING JOURNAL. 2019;1(2):140-7.

Jaelani. Aromaterapi. Jakarta: Pustaka Populer. 2009.

Koensoemardiyah. Aromaterapi untuk Kesehatan dan Kecantikan. Yogyakarta: Lily Publisher. 2009.

Kementerian Kesehatan RI. Buku Kesehatan Ibu dan Anak. Jakarta: Kemenkes RI.2015.

Kianpour, M., Akram Mansouri, Tayebeh Mehrabi \& Gholamreza asghari, 2016. Effect of Lavender Scent Inhalation On Prevention Of Stress, Anxiety and Depression In The Postpartum Period. Iranian Journal of Nursing and Midwifery Research. 2016;21(2)197201.

Kristanti EE. Pengaruh aromaterapi lavender terhadap penurunan derajat kecemasan pada lansia di panti wredha st yoseph kediri. J Penelit Stikes RS Baptis Kediri. 2010;3(2):94-100

Maryunani, A. Management kebidanan. Jakarta: CV.Trans Info Media.2016.

McCullough JEM, Liddlea SD, Closeb C, Sinclaira M, Hughes CM. Reflexology: A randomised controlled trial investigating the effects onbeta-endorphin, cortisol and pregnancy related stress. ESEVIER.2018;31:76-84.

Mochtar R. Obstetri fisiologi jilid I. Jakarta: EGC. 2008

Salamati A, Mashouf S, Sahbaei F, Mojab F. Effects of Inhalation of Lavender Essential Oil on Open-heart Surgery Pain. Iran $\mathrm{J}$ Pharm Res IJPR . 2014;13(4):1257-61. Available from: http://www.ncbi.nlm.nih.gov/pubmed/25 $\underline{587315}$.

Sheikhan F,dkk. Episiotomy pain relief: Use of Lavender oil essence in primiparous Iranian women.ELSEVIER.2012;18:6670.

Smeltzer, Suzanne C \& Bare, Brenda G. Keperawatan Medikal Bedah. Jakarta: EGC. 2002.

Tournaire M, Theau-Yonneau A. Complementary and Alternative Approaches to Pain Relief during Labor. Ecam.2007;4(4):409-17.

Widayani W. Aromaterapi lavender dapat menurunkan intensitas nyeri perineum pada ibu post partum. Journal Ners and Midwifery Indonesia.2016;4(3):123-8.

Yazdkhastia M, Pirak A. The effect of aromatherapy with lavender essence on severity of laborpain and duration of labor in primiparous women. ELSEVIER. 2016;25.81-6. 